\title{
VETORES DE EXPANSÃO URBANA EM ARACAJU-SE, BRASIL Produção (entrelaçada) de cidade pelo Estado e mercado imobiliário
}

\author{
Sarah Lúcia Alves França \\ Departamento de Arquitetura e Urbanismo/Universidade Federal de Sergipe, Brasil \\ sarahfranca@ig.com.br
}

\section{RESUMO}

Esta pesquisa tem como objetivo analisar a produção habitacional oriunda atuação do mercado imobiliário e do Estado e apontar os vetores de expansão urbana em Aracaju-SE, Brasil, entre 2000 a 2014. A capital de Sergipe apresentou dinamismo na produção do espaço a partir da atuação do mercado, de forma mais intensa, a partir da promulgação do Plano Diretor, em 2000, mediante apoio do Estado, através de legislações permissivas, ampliação da infraestrutura viária e incentivo ao crédito imobiliário. Verificou-se um expressivo aumento do número de empreendimentos imobiliários, resultando no adensamento de bairros urbanizados e valorizados, e, por outro lado, a expansão fragmentada e periférica em áreas sem infraestrutura. Para o desenvolvimento deste, foi realizado levantamento bibliográfico, coleta de dados nos órgãos públicos, organizados sob a forma de tabelas e cartografias, que permitiu quantificar e espacializar a dinâmica urbana em Aracaju.

Palavras-chave: Produção Habitacional; Mercado Imobiliário; Estado; Vetores de Expansão Urbana.

\begin{abstract}
This research aims to analyze the housing production from the real estate market and the State and to point out the vectors of urban expansion in Aracaju-SE, Brazil, between 2000 and 2014. The capital of Sergipe presented dynamism in the production of space from the performance of the market, more intensely, after the promulgation of the Master Plan in 2000, through State support, through permissive legislation, expansion of road infrastructure and encouragement of real estate credit. There was a significant increase in the number of real estate developments, resulting in the densification of urbanized and valued neighborhoods, and, on the other hand, the fragmented and peripheral expansion in areas without infrastructure. For the development of this, a bibliographic survey was carried out, data collection in public agencies, organized in the form of tables and cartographies, which allowed quantify and spatialize the urban dynamics in Aracaju.
\end{abstract}

Keywords: Housing Production; Real estate market; State; Vectors of Urban Expansion. 


\section{INTRODUÇÃO}

Esta pesquisa tem como objetivo analisar a produção habitacional oriunda da atuação do mercado imobiliário e do Estado e apontar os vetores de expansão urbana em Aracaju-SE no recorte temporal de 2000 a 2014. Além disso, verifica como a ação pactuada do Estado privilegia e/ou induz a inserção dos empreendimentos habitacionais construídos em determinadas áreas pelo mercado privado, criando uma cidade desigual, com segregação de ricos e de pobres, além da oferta de infraestrutura diferenciada.

O estudo parte do princípio de que a produção urbana capitalista é resultado de processos privados e/ou públicos provenientes da atuação dos agentes modeladores do espaço e suas formas variadas de apropriação da terra, com produtos habitacionais fechados. Neste sentido, é importante observar a terra como mercadoria, que varia de acordo com a sua localização, presença de elementos ambientais, intervenções públicas e privadas, e ainda a legislação urbanística.

A capital do Estado de Sergipe apresentou um dinamismo na produção do espaço urbano para reprodução do capital, sobretudo de forma mais intensa, a partir dos anos 2000 (após promulgação do Plano Diretor), mediante apoio do Estado, através de legislações urbanísticas, financiamentos em intervenções urbanas e incentivo ao crédito imobiliário pelo Governo Federal. Nesse período, verificou-se um expressivo aumento do número de licenciamentos de empreendimentos imobiliários, somados ao fortalecimento de grandes construtoras, resultando na busca por novas "áreas de consumo", que ocasionou o adensamento de bairros urbanizados, ou criou áreas novas em bairros distantes do centro, gerando novas configurações sócioespaciais.

Para o desenvolvimento deste estudo, oriundo de uma pesquisa de doutoramento, foi realizado um levantamento bibliográfico sobre a temática abordada, ampla coleta de dados nos órgãos públicos, referentes aos empreendimentos imobiliários licenciados e as intervenções do Estado, especialmente legislação e implantação de equipamentos públicos e sistema viário. Esses dados foram organizados sob a forma de tabelas, que quantificaram o volume e características da ocupação, além da produção de cartografia, que permitiu espacializar a dinâmica do adensamento e expansão urbana em Aracaju.

\section{ESTADO E MERCADO IMOBILIÁRIO: PRODUÇÃO CAPITALISTA DO ESPAÇO URBANO DE ARACAJU}

Aracaju, desde o ano 2000, experimentou um crescimento que tem configurado a implosão-explosão urbana, resultando numa forte segregação sócioespacial e fragmentação espacial. Isso significou para os mais pobres, a dificuldade de acesso aos serviços de infraestrutura, como transporte, saneamento e drenagem, além dos equipamentos de saúde, educação e lazer. Somado a isso, as menores oportunidades de emprego e renda e o aumento da violência acarretaram sérios entraves no acesso à cidade justa e igualitária, acentuando a formação de uma periferia sem a mínima qualidade de vida, produzida pelo mercado informal de moradia.

Por outro lado, a autossegregação se fortaleceu, especialmente em espaços cada vez mais fechados e dotados de segurança, como os condomínios residenciais e shoppings centers, se distanciando cada vez mais do caos, da violência e da pobreza. Essa situação marcou uma cidade heterogênea, com formas habitacionais diversas em função dos níveis de renda, acarretando uma ocupação diferenciada do espaço. Essas contradições que permeiam a cidade é o que Lefebvre (2001) denomina como "negatividades do urbano".

Essas divergências socioeconômicas são muito grandes e isso é refletido no espaço de forma segregada e na estruturação urbana da capital. Assim, constatou-se uma variedade de empreendimentos imobiliários, entremeados nos vazios, causando descontinuidade na malha, que oneram a implantação de infraestrutura e a oferta de serviços públicos pelo Estado.

A apropriação diferenciada de áreas através da inserção das três tipologias imobiliárias (condomínios horizontais e verticais, loteamentos fechados) e dos conjuntos habitacionais ocorreu atendendo externalidades, como estoque da terra, valor fundiário e o fator localização com as condições ambientais, regulação urbanística e infraestrutura. 
Em Aracaju, operam vários agentes imobiliários responsáveis pela produção, ocupação e comercialização do espaço urbano, alterando as formas de uso do solo em detrimento dos seus próprios interesses, associados à valorização da terra. Além disso, Estado acumula funções, quando provém moradia social, constrói avenidas, reformula eixos viários e regulamenta o espaço urbano através da legislação que restringe ou permite a ocupação em zonas. Essas intervenções públicas também contribuíram na expansão e adensamento de bairros e na formação de novos vetores de crescimento urbano.

Após a promulgação do Plano Diretor, em 2000, até 2014, verificou-se o licenciamento de 519 empreendimentos fechados, sendo mais de $80 \%$ de responsabilidade do mercado imobiliário, resultando em uma oferta de mais de 62 mil unidades habitacionais. A apropriação intensiva do espaço dá-se em função da produção habitacional ter se voltado predominantemente para a construção de prédios, em decorrência da escassez de terras e do direcionamento do empreendimento para grupos de renda que priorizam viver em áreas mais adensadas, mais centrais. Sendo assim, observa-se que a construção de condomínios verticais corresponde a $64 \%$ do total de empreendimentos licenciados (Gráfico 1 e 2).

\begin{tabular}{|c|c|c|c|c|}
\hline & Empreendimentos & $\%$ & $\begin{array}{c}\text { Unidades } \\
\text { Habitacionais }\end{array}$ & $\%$ \\
\hline \multicolumn{5}{|c|}{ Estado } \\
\hline Projetos Habitacionais & 06 & 1,15 & 6.704 & 10,70 \\
\hline PAR & 39 & 7,51 & 6.850 & 10,95 \\
\hline PMCMV & 49 & 9,44 & 9.986 & 15,95 \\
\hline Total & 94 & 18,11 & 23.540 & 37,60 \\
\hline \multicolumn{5}{|c|}{ Mercado Imobiliário } \\
\hline Condomínio Vertical & 334 & 64,35 & 33.832 & 54,06 \\
\hline Condomínio Horizontal & 65 & 12,52 & 2.783 & 4,44 \\
\hline Loteamento Fechado & 26 & 5,00 & 2.432 & 3,88 \\
\hline Total & 425 & 81,87 & 39.047 & 62,39 \\
\hline Total Geral & 519 & 100 & 62.587 & 100 \\
\hline
\end{tabular}

Gráfico 1: Aracaju, Empreendimentos e Unidades Habitacionais por Agente e Tipologia, 2000 - 2014

Elaboração Sarah França, 2016, a partir de dados coletados em pesquisa de campo e na Coordenadoria de Urbanismo da Empresa Municipal de Obras e Urbanização - EMURB/PMA, 2015; Prefeitura Municipal e Governo do Estado; CAIXA (2009; 2015).

É nítida a segregação espacial dos empreendimentos construídos pelo mercado imobiliário e pelo Estado. A seleção das áreas pela iniciativa privada tem relação com a concentração prévia de população de maior renda e maior disponibilidade de infraestrutura, comércio e serviços, como ocorre nas zonas leste e sul, até o bairro Aeroporto. No caso dos bairros situados ao longo da faixa litorânea e às margens dos Rios Sergipe e Poxim (como 13 de Julho, Jardins, Coroa do Meio e Atalaia), o mercado se apropriou dessas áreas, em função da exploração do potencial paisagístico, trazendo empreendimentos imobiliários destinados aos moradores de renda mais alta (Gráfico 2).

A construção de grandes torres fechadas intramuros nessas áreas mais valorizadas permitiu enormes ganhos ao setor imobiliário, por possibilitar maior lucratividade em função do maior número de unidades habitacionais em um único terreno. Essa fragmentação fundiária, proporcionada a partir da instituição de uma nova forma de apropriação da terra, que é o condomínio, tornou-se elemento fundamental no avanço das relações capitalistas de produção do espaço.

O setor imobiliário pouco se interessou por atuar em bairros da zona norte, assinalados por uma ocupação mais popular, com assentamentos precários e irregulares. Isso tendeu a reduzir os interesses de investimentos, embora haja uma participação do setor privado na produção habitacional subsidiada pelos Programa de Arrendamento Residencial e o Programa Minha Casa Minha Vida.

Por sua vez, a atuação do Estado ocorreu na periferia dos bairros apropriados pelo mercado, concentrandose na porção norte, acima das avenidas Coelho Campos e São Paulo, como divisor desta zona. Além dessa, duas outras áreas apresentaram empreendimentos habitacionais construídos com a participação da Prefeitura, com recursos federais, por construtoras locais, a exemplo do Jabotiana, situado ao oeste, e, ao sul, na porção norte da Zona de Expansão Urbana, os empreendimentos do PAR e do PMCMV estão entremeados pelos condomínios horizontais e loteamentos fechados (Gráfico 2). 


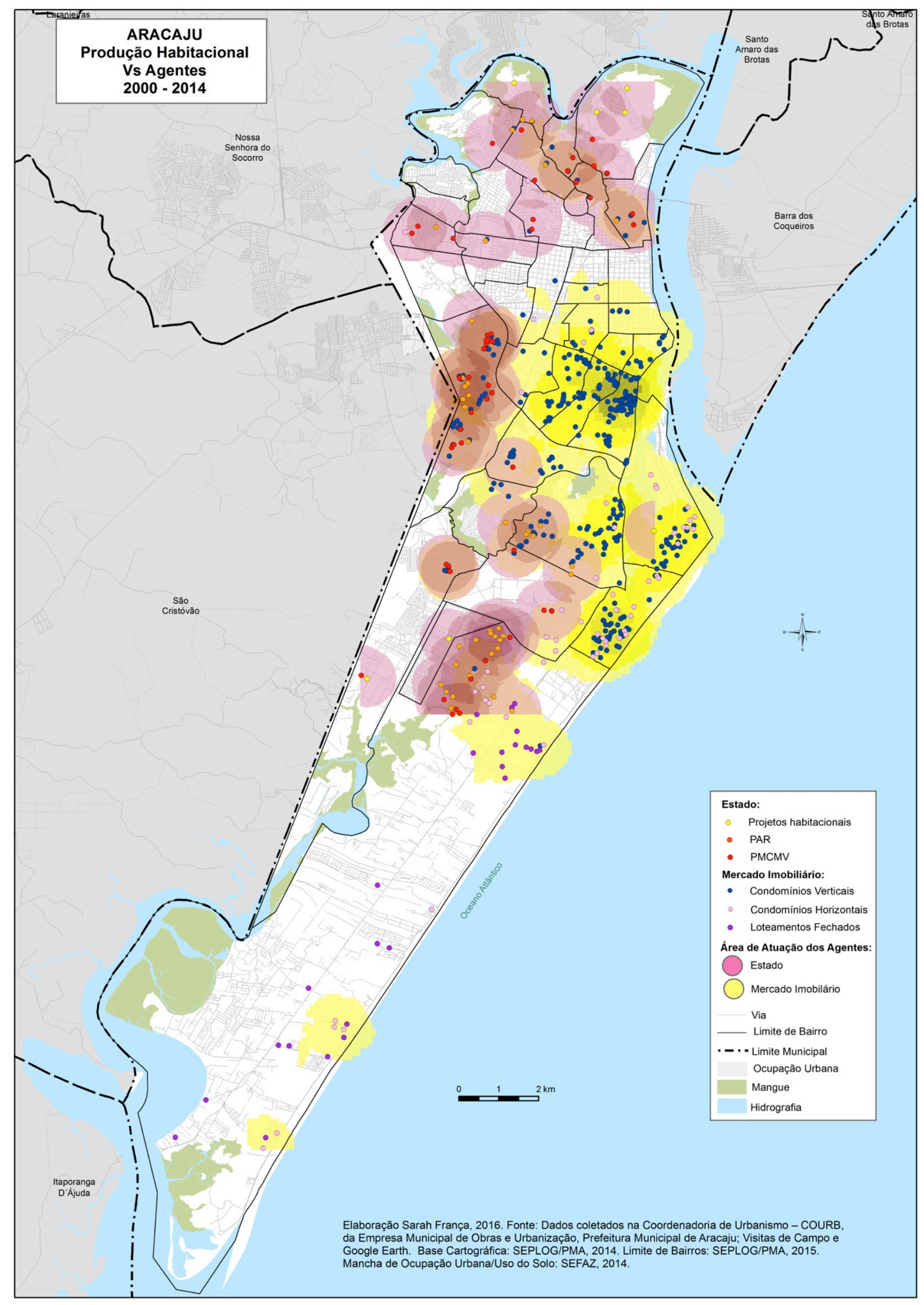

Gráfico 2: Aracaju, Produção Habitacional X Agentes, 2000-2014. Elaboração Sarah França, 2016. 
Por apresentar um vínculo intrínseco com a apropriação da terra, a habitação tem o espaço como condição fundamental para reprodução do capital, determinando transformações nas relações sócioespaciais. Por isso, a atuação concentrada do capital nos espaços vazios gerou uma maior valorização dos imóveis devido à escassez do solo, que foi estimulada por aqueles que detém o monopólio da distribuição do espaço para as moradias.

Construtoras de médio e grande porte demandam, em sua maioria, por espaços urbanizados, com vizinhança para consumo e investimentos, com interesse em obter rendimentos também advindos da valorização fundiária, ainda que mantenham vazios, em meio ao parcelamento do solo, com abertura de novas vias e logradouros públicos.

Essas empresas se associaram às de porte nacional e regional, como a parceria entre Norcon e Rossi, ou entre firmas locais e regionais, como FelizCidade e Celi. Esse entrelaçamento trouxe uma ampliação na gama de oferta de produtos imobiliários para diferentes classes sociais, em diferentes bairros. Aquelas de pequeno porte direcionam seus produtos a um público de nível de renda menor, sendo os empreendimentos construídos em áreas periféricas ao norte e oeste, com baixo valor fundiário, sem oferta de infraestrutura e acessibilidade, a fim de obter o lucro após a instalação dos primeiros empreendimentos.

Para realizar a comercialização dos seus produtos, as construtoras procuram estimular o comprador, e para tal, limitam-se a garantir condições de acessibilidade, sendo a infraestrutura de responsabilidade do poder público. Esse agente procura maximizar seus lucros pela apropriação dos benefícios incorporados pelo Estado e, para isso, utiliza-se de estratégias que consistem em implantar empreendimentos fechados, em bairros distantes das áreas centrais, para obtenção de lucro pelo parcelamento atrelado às futuras intervenções públicas, provenientes de cobranças e pressões desses novos moradores.

Os empreendimentos imobiliários destinados às classes de renda mais elevada e de tipologia verticalizada se concentram na porção leste da cidade, sobretudo entre os bairros 13 de Julho, Atalaia, ao sul e atingindo o Jabotiana, ao oeste. Nas áreas mais próximas ao Centro, e especialmente ao bairro 13 de Julho e Jardins, os imóveis têm valor elevado, resultando numa ocupação vertical que multiplica a quantidade de solo. Esses condomínios fechados estão próximos uns aos outros, e à medida que vão se afastando desses bairros, vão apresentando dimensões menores das unidades habitacionais, consequentemente, destinando-se aos grupos de renda média, especialmente aqueles promovidos pelos Programas de Arrendamento Residencial e o recente Minha Casa Minha Vida.

Ainda em relação à verticalização, o resultado evidente é a apropriação de áreas bastante heterogêneas, como 13 de Julho/Jardins/Grageru, Luzia/Ponto Novo/Suiça e Jabotiana. Dos 175 empreendimentos construídos na zona leste-oeste para faixas de renda diferenciadas, 65 foram localizados nos bairros Luzia, Ponto Novo, Jabotiana apontando a direção de novos vetores de adensamento e de expansão urbana. Além das diferentes características da localização, a diversidade de incorporadores resultou em variações nas tipologias, na qualidade dos materiais, no tamanho e nos atributos internos: área útil, área dos cômodos, número de quartos e de banheiros.

Alguns desses bairros, como o Jabotiana, Luzia e Ponto Novo foram marcados pela modificação da paisagem horizontal imperada pelas residências unifamiliares, que foram, ao longo desses 15 anos, trocadas pelos conjuntos de torres de edifícios implantados em locais como a Alameda das Árvores, no Luzia ou no Ponto Novo, na Avenida Rio de Janeiro.

Outra opção refere-se aos condomínios horizontais e loteamentos fechados, em sua maioria direcionados para população de renda mais elevada, caracterizados pela segregação e homogeneização de níveis econômicos, além de se constituírem, em mansões para veraneio e finais de semana, sobretudo aquelas localizadas no extremo sul. Sua implantação demanda glebas ou lotes com maior área e localização privilegiada com a presença de amenidades naturais. Esse precedente reduz sua oferta em áreas mais centrais, distanciando-os para fora da malha urbana consolidada, e criando assim, novos vetores de expansão urbana, como a Zona de Expansão Urbana.

Examinando a produção habitacional por bairros, foi possível dividir em três períodos. Alguns bairros tiveram uma progressão acentuada na quantidade de empreendimentos licenciados, como o Jabotiana, Atalaia, Coroa do Meio, Luzia e Farolândia. O primeiro apresentou, entre 2000 a 2004, apenas 1 condomínio vertical, e nos demais períodos, 14 e 12 respectivamente (Gráfico 3). 


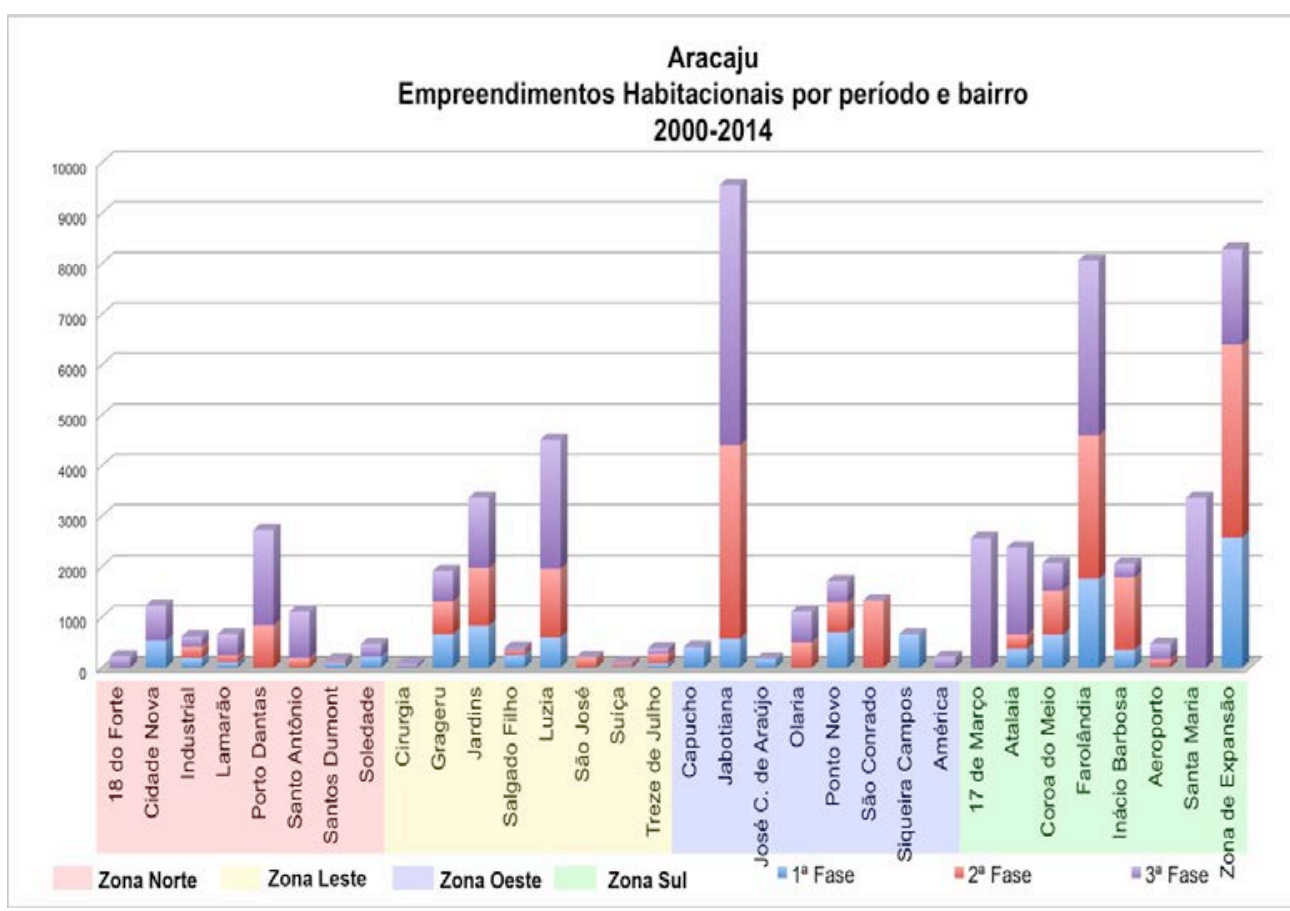

Gráfico 3: Aracaju, Produção Habitacional, Periodização por bairros. 2000-2014.

Elaboração Sarah França, 2016, a partir de dados coletados em pesquisa de campo e na Coordenadoria de Urbanismo da Empresa Municipal de Obras e Urbanização - EMURB/PMA, 2015; Prefeitura Municipal e Governo do Estado; CAIXA (2009; 2015).

Outro exemplo de ascensão foi o bairro Atalaia que, no último período, teve a quantidade de empreendimentos licenciados correspondendo ao dobro dos anteriores. No bairro Coroa do Meio, apesar de serem empreendimentos fechados de pequeno porte (a maioria condomínios horizontais tipo "duplex"), a quantidade destes foi fortemente notada, sobretudo a partir do segundo período. $\mathrm{O}$ bairro Luzia, inicialmente, com 5 condomínios verticais, atingiu o número de 15 , nos últimos anos, enquanto no bairro Farolândia, o número duplicou a cada ciclo. Os bairros que tiveram a maior produção habitacional foram: Grageru, Jardins, Luzia, Jabotiana, Ponto Novo, Atalaia, Farolândia, Inácio Barbosa, ZEU.

\section{LEGISLAÇÃO URBANA COMO PONTO-CHAVE NA FORMAÇÃO E CONSOLIDAÇÃO ESPACIAL DE ARACAJU}

De fato, alguns aspectos influenciaram no adensamento e expansão urbana em Aracaju, como o estabelecimento de normas de controle de uso e ocupação do solo, permitindo e restringindo formas de apropriação de determinadas áreas, a realização de obras e intervenções urbanísticas, especialmente no tocante ao sistema viário e implantação de equipamentos coletivos e, por fim, o valor da terra. Esses elementos se constituíram importantes para a escolha das áreas utilizadas pelo mercado imobiliário, para construção de condomínios, ou pelo Estado para implantação de conjuntos habitacionais.

Enfatiza-se a influência da legislação urbanística, especialmente das leis complementares inconsistentes e retalhadas, que contrariaram as determinações do Plano Diretor, estabelecendo diretrizes que direcionaram as formas de ocupação ou parâmetros urbanísticos que priorizaram determinados grupos econômicos. Uma dessas foi a sucessão de leis que determinaram gabaritos de altura para edificações multifamiliares, as Leis Complementares $n^{\circ} 62 / 2003, n^{\circ} 74 / 2008$ e $n^{\circ} 132 / 2014$, cujas distorções tiveram início ainda nos anos 1970, com a Lei $n^{\circ} 466$, Resolução n 38/1977 e Decreto no 154/1999, criando uma colcha de retalhos na legislação urbanística de Aracaju e dificultando seu cumprimento.

Quando se sobrepõe o zoneamento apresentado pelo Plano Diretor à produção habitacional, observa-se que embora as diretrizes e índices urbanísticos sirvam para direcionar ou controlar a ocupação, o alto coeficiente de aproveitamento básico de três, determinado para toda cidade, não propiciou a aplicação da Outorga Onerosa do Direito de Construir. Isso resultou na não diferenciação da permissividade da legislação, estimulando a ocupação, em detrimento a outros fatores, em bairros de interesse dos compradores dos produtos imobiliários, como aqueles localizados na Zona de Adensamento Básico - ZAB 2. É aí que se concentram 365 empreendimentos, correspondendo à cerca de 70\% do total produzido entre 2000 a 2014 (Gráficos 4 e 5). 


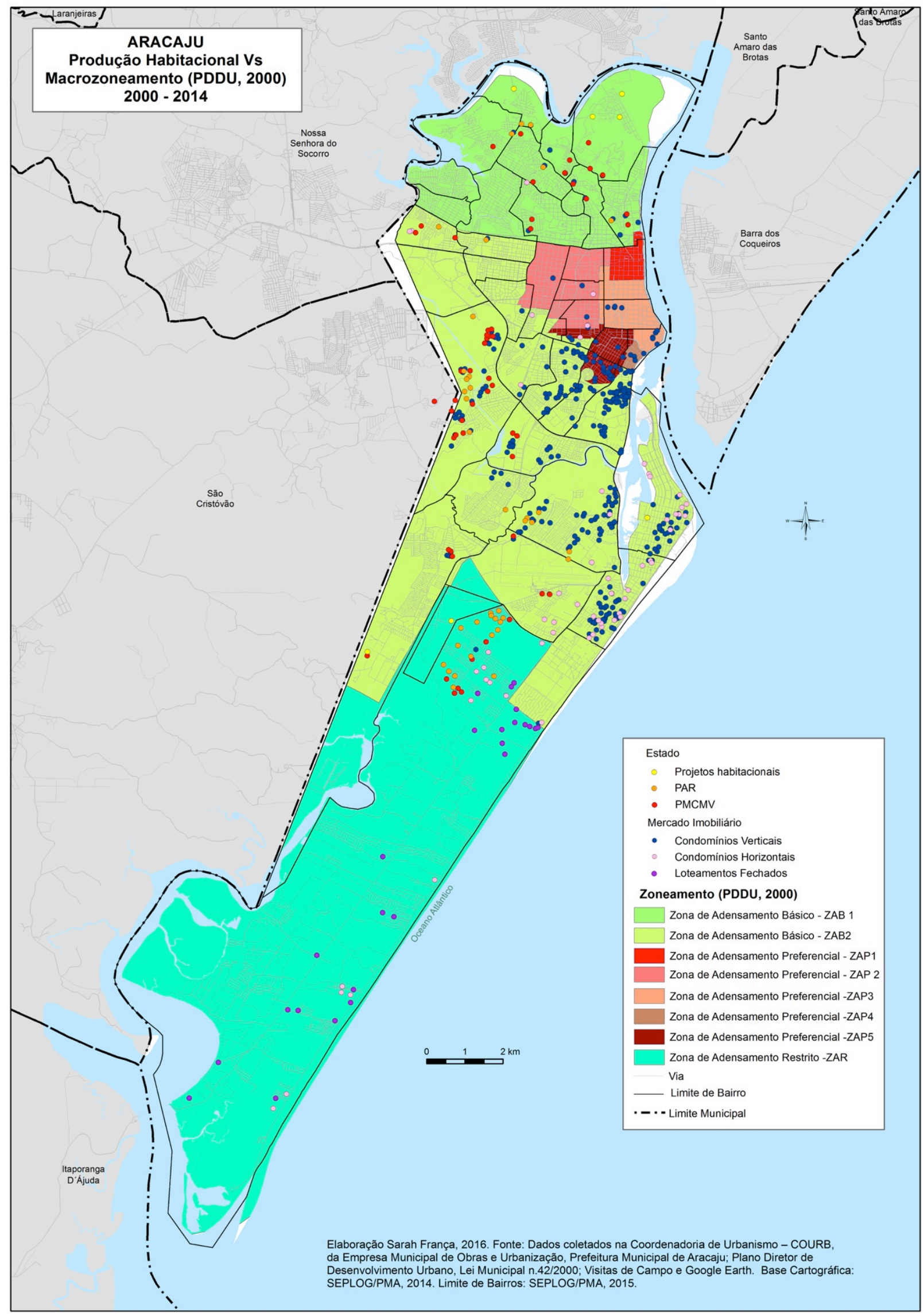

Gráfico 4: Aracaju, Produção Habitacional e Macrozoneamento, 2000-2014. Elaboração Sarah França, 2016. 


\begin{tabular}{|c|c|c|c|c|c|}
\hline \multicolumn{2}{|c|}{} & $\begin{array}{c}\text { Área } \\
\left(\mathbf{k m}^{2}\right)\end{array}$ & $\%$ & Empreendimentos & $\%$ \\
\hline \multirow{2}{*}{ ZAB } & ZAB 1 & 21,81 & 13,34 & 37 & 7,13 \\
\cline { 2 - 6 } & ZAB 2 & 53,06 & 32,46 & 365 & 70,32 \\
\hline \multicolumn{2}{|c|}{ ZAP } & 8,89 & 5,46 & 50 & 9,63 \\
\hline \multicolumn{2}{|c|}{ ZAR } & 79,67 & 48,74 & 67 & 12,92 \\
\hline
\end{tabular}

Gráfico 5: Aracaju, Empreendimentos e Unidades Habitacionais por Zonas de Adensamento, 2000 - 2014

Elaboração Sarah França, 2016, a partir de dados coletados em pesquisa de campo e na Coordenadoria de Urbanismo da Empresa Municipal de Obras e Urbanização - EMURB/PMA, 2015; Prefeitura Municipal e Governo do Estado; CAIXA (2009; 2015).

A diferenciação que deveria haver entre $Z A B 1$ e $Z A B$ 2, na prática, não funcionou. Apesar de apresentar cenários bastante divergentes, nessas zonas o coeficiente de aproveitamento máximo varia entre 3,00 e 4,00, sendo que a Outorga Onerosa do Direito de Construir é isenta para toda a cidade, até esse último índice. Outros fatores foram responsáveis pela não apropriação da terra na zona norte pelo mercado imobiliário, como os níveis de renda da população e a oferta de infraestrutura disponível, com poucas melhorias nesses anos.

A Zona de Adensamento Básico 1 contempla bairros localizados na zona norte, como Porto D'Antas, Lamarão, Industrial, cujas famílias pertencem a classe de renda média e baixa. A grande maioria dos 37 empreendimentos construídos são fruto de programas habitacionais, como o PAR e o PMCMV, ou projetos realizados pela Prefeitura Municipal, contrapondo-se às tipologias habitacionais implantadas na ZAB 2, de condomínios verticais direcionados às classes de renda média e alta, construídos, em sua grande maioria, pelo mercado imobiliário, o maior agente interessado e atuante neste espaço.

Quanto à dotação de infraestrutura e acessibilidade esses bairros apresentavam deficiência, de acordo com o Plano Diretor. Porém, atualmente, a oferta de saneamento básico, serviços públicos e equipamentos coletivos na ZAB 2 é crescente, em função das obras de melhorias no esgotamento sanitário e sistema viário, realizadas nos últimos anos, acarretando um aumento do valor da terra. Diante disso, o interesse do mercado aumentou, trazendo para esses locais novos empreendimentos fechados, favorecidos também pela proximidade de espaços coletivos, como o Calçadão da 13 de Julho e o Shopping Jardins.

No caso da Zona de Adensamento Preferencial - ZAP, conforme suas diretrizes de incentivo à ocupação, dada a oferta de infraestrutura, equipamentos urbanos e boa acessibilidade, deveria receber mais empreendimentos, proporcionando um adensamento maior através do coeficiente de aproveitamento máximo variando entre 4,00 e 6,00. Entretanto, o estímulo à instalação de uso residencial, nas áreas comerciais e de serviços, pelo mercado tem sido mínimo, em decorrência da exiguidade de vazios urbanos e com dimensões que não permitem a implantação de empreendimentos imobiliários. Sendo assim, dos 50 condomínios que foram construídos, 45 são de tipologia vertical, e o restante, são condomínios horizontais de pequeno porte, exceto o Cond. Vivendas de Aracaju, no bairro Siqueira Campos, com 485 unidades. Os demais, localizados nos bairros Suíça e Cirurgia, dispõem de 6 a 16 unidades habitacionais.

Na Zona de Adensamento Restrito - ZAR (equivalente à grande parte da Zona de Expansão Urbana), cujo conceito refere-se ao déficit de infraestrutura e presença de restrições ambientais, foram licenciados 67 empreendimentos (12\% do total), quantidade superior àquela da ZAB 1 e ZAP. O interesse do mercado aumentou progressivamente em função do baixo valor da terra, comparado às demais similares, pela paisagem ambiental e proximidade aos elementos naturais e às áreas mais valorizadas da zona leste e sul, como 13 de Julho, Jardins e Atalaia. Todavia, o grande entrave da ZAR é o antagonismo entre legislação (diretrizes de estruturação urbana) e realidade, em função dos índices urbanísticos elevados, que beneficiam os agentes produtores da moradia, desconsiderando a capacidade do saneamento básico (esgotamento sanitário e especialmente drenagem). A permissividade das normas para parcelamento do solo é significativa tendo em vista o coeficiente de aproveitamento máximo até 3,5, a taxa de permeabilidade equivalente a 5\% e a de ocupação com 90\% (França, 2011, 2016).

Quanto à estruturação urbana, verifica-se que a definição do coeficiente de aproveitamento elevado patrocinou os interesses dos incorporadores imobiliários, sobretudo favorecendo a ZAP 4 e 5, ZAB 2 e ZAR, que corresponde a bairros valorizados e com poucos vazios urbanos, mais centralizados, portanto sendo, ao longo desses anos, adensados. Ao comparar os vetores de expansão até 1999, com os atuais, comprova-se que o Macrozoneamento estabelecido pelo Plano Diretor, aprovado em 2000, deu continuidade à tendência do crescimento em direção oeste e sul, adotada até então. Os bairros na porção oeste da ZAB 2, como o Jabotiana e a Zona de Expansão Urbana, na ZAR, ambos com infraestrutura quase ausente e sistema viário fragmentado, mas com índices urbanísticos elevados, foram alvo do mercado imobiliário e do Estado, no 
tocante à produção de empreendimentos habitacionais. Diante disso, França (2011: 171) reflete que "faz-se necessário estabelecer critérios, além de fortalecer diretrizes e instrumentos da legislação. O mais grave é a negligência, ao definir o mesmo coeficiente para toda a cidade, uma vez que as zonas têm características diferentes e peculiares, principalmente quando se refere à ZEU, que dispõe de infraestrutura precária e condições ambientais muito frágeis, mas com forte tendência ao adensamento".

Ainda que a legislação tenha determinado diretrizes de adensamento por zonas, em muitas áreas em que foram previstas especificidades, estas são insuficientes e ineficientes. Todavia, a normativa não incorporou as reais condições de cada zona, a fim de diminuir conflitos entre ocupação e manutenção das características ambientais, acentuando a incidência de alagamentos e inundações, como aconteceu nos últimos anos principalmente no bairro Jabotiana e na ZEU. Neste caso, o Plano Diretor "contempla a problemática urbana e ambiental e preconiza o adensamento restrito na ZEU, enfatizando a priorização de verbas orçamentárias no resgate do déficit de infraestrutura, equipamentos urbanos e serviços comunitários. [...] Na prática, vem ocorrendo um descompasso entre ocupação e uso do solo e dotação de recursos para infraestrutura, havendo um distanciamento da verdadeira restrição ao adensamento, considerando a capacidade de saneamento ambiental, especialmente esgotamento sanitário e drenagem urbana" (França, 2011: 171).

O entrelaçamento da produção habitacional e das intervenções realizadas pelo Estado é notório, sobretudo nas áreas já adensadas, onde houve a construção de pontes, que viabilizaram a aproximação entre dois bairros, preenchendo vazios, como no caso da ponte Gilberto Vilanova, sobre o Rio Poxim, interligando os bairros Farolândia e Inácio Barbosa. Essa intervenção teve como resultado a transformação do uso residencial em comércio e serviços ao longo da Avenida Paulo VI, e nessa proximidade, implantados novos condomínios verticais.

A construção da ponte Construtor João Alves que conecta Aracaju e Barra dos Coqueiros privilegiou a implantação de loteamentos fechados de luxo, neste município, direcionados a uma clientela de renda mais elevada, que mora na capital. Diferentemente do resultado da implementação da Ponte Joel Silveira, no Mosqueiro, que interliga Aracaju a Itaporanga d'Ajuda, em que a intervenção não trouxe alterações na produção habitacional de mercado, nessas áreas.

Outras intervenções pontuais, como a Revitalização do Farol Estuarino na Farolândia, Reforma da Orlinha do bairro Industrial favoreceram a chegada de novos empreendimentos habitacionais nas suas proximidades, dinamizando o entorno com outros usos, como comércios e serviços, e além disso, acrescendo valor à terra.

Alguns bairros foram isentos de intervenções urbanas, mas tiveram um fortalecimento na produção habitacional, sob atuação do mercado, remodelando o espaço através do adensamento de vazios urbanos como o Jardins, Grageru e Luzia. No caso dos bairros Coroa do Meio e Atalaia que concentram condomínios verticais e horizontais, apesar de terem sido realizadas diversas obras na Orla de Atalaia durante os últimos anos, essas se constituíram em reformas nas edificações ou acréscimo de algumas, como as quadras de tênis, delegacia, pista de kart, parque infantil, estacionamento, entre outros, não sendo consideradas como elementos de remodelação para o bairro. De fato, o que se identificou foi a força da legislação que abriu frentes para a ocupação, em função da desativação do Farol Estuarino da Farolândia para a Coroa do Meio.

Por fim, é relevante frisar que as avenidas Santa Gleide (em obras) e a Perimetral (em projeto) apontarão novas tendências de ocupação nos bairros limítrofes a Aracaju e Nossa Senhora do Socorro, bem como São Cristóvão nas imediações do bairro Jabotiana, fortalecendo o fenômeno de metropolização iniciado nas décadas de 1970 e 1980, conforme assinalou França (1999).

\section{VETORES DE ADENSAMENTO E DE EXPANSÃO URBANA DE ARACAJU: PARA ONDE ESTÁ CRESCENDO A CIDADE?}

Para comprovar o direcionamento da expansão urbana foram selecionados os dez bairros que mais receberam empreendimentos e unidades habitacionais, o que permitiu examinar que alguns apontados apresentam aspectos como grande quantidade de vazios que se caracterizam como estoque de terra, a exemplo da ZEU, Jabotiana e Porto D'Antas. Outra questão foi a permissividade da legislação que incentivou o adensamento de bairros como Jardins, 13 de Julho, Luzia, Farolândia na Zona de Adensamento Básico. A apuração desses dados gerou uma classificação dos bairros de maior investimento do mercado imobiliário, demonstrando a direção e caracterização dos vetores de adensamento e de expansão urbana, em termos quantitativos (Gráfico 6). 
Nesse âmbito, a Zona de Expansão se destaca não só como a que mais recebeu empreendimentos, mas com a segunda posição em quantidade de unidades habitacionais licenciadas, com 8.292, perdendo apenas nesse quesito para o bairro Jabotiana, em franco crescimento. Nesses dois, a valorização fundiária tem crescido substancialmente, acompanhada pelas intervenções públicas e particulares que substituem terrenos por empreendimentos multifamiliares. O bairro Farolândia assume a terceira posição em ambas as classificações, bem como Coroa do Meio, Atalaia e Luzia (Gráfico 6).

\begin{tabular}{|c|c|c|c|c|c|}
\hline \multicolumn{3}{|c|}{ Empreendimentos } & \multicolumn{3}{|c|}{ Unidades Habitacionais } \\
\hline Classificação & Bairro & Quantidade & Classificação & Bairro & Quantidade \\
\hline $1^{\circ}$ & Zona de Expansão & 69 & $1^{\circ}$ & Jabotiana & 9.953 \\
\hline $2^{\circ}$ & Jardins & 64 & $2^{\circ}$ & Zona de Expansão & 8.292 \\
\hline $3^{\circ}$ & Farolândia & 58 & $3^{\circ}$ & Farolândia & 8.061 \\
\hline $4^{\circ}$ & Atalaia & 56 & $4^{\circ}$ & Luzia & 4.512 \\
\hline $5^{\circ}$ & Jabotiana & 51 & $5^{\circ}$ & Jardins & 3.379 \\
\hline $6^{\circ}$ & Coroa do Meio & 42 & $6^{\circ}$ & Santa Maria & 3.357 \\
\hline $7^{\circ}$ & Luzia & 29 & $7^{\circ}$ & Porto D'Antas & 2.725 \\
\hline $8^{\circ}$ & Grageru & 27 & $8^{\circ}$ & 17 de Março & 2.562 \\
\hline $9^{\circ}$ & Inácio Barbosa & 15 & $9^{\circ}$ & Atalaia & 2.318 \\
\hline $10^{\circ}$ & 13 de Julho & 13 & $10^{\circ}$ & Coroa do Meio & 2.069 \\
\hline \multicolumn{2}{|r|}{ Total } & 424 & \multicolumn{2}{|r|}{ Total } & 47.288 \\
\hline \multicolumn{2}{|r|}{ Total Aracaju } & 519 & \multicolumn{2}{|r|}{ Total Aracaju } & 62.587 \\
\hline \multicolumn{2}{|r|}{$\%$} & 81,69 & \multicolumn{2}{|r|}{$\%$} & 75,55 \\
\hline
\end{tabular}

Gráfico 6: Aracaju, Classificação dos Bairros por empreendimentos e unidades habitacionais, 2000 - 2014

Elaboração Sarah França, 2016, a partir de dados coletados em pesquisa de campo e na Coordenadoria de Urbanismo da Empresa Municipal de Obras e Urbanização - EMURB/PMA, 2015.

Entre os anos 2000 e 2014 foi constatada a formação de novos vetores de expansão urbana e o fortalecimento de alguns existentes até 2000 , em direção aos principais eixos viários. No caso dos vetores que se formam ao norte, partindo do bairro Industrial, no sentido dos bairros Porto D'Antas, Lamarão e Bugio é relevante recordar a proximidade com o limite de Nossa Senhora do Socorro, além da presença de fortes ligações viárias entre a capital e este município, situadas, nos arredores dos principais conjuntos habitacionais construídos pelo Estado (Gráfico 7).

São bairros destacados pelo desinteresse do setor imobiliário por abrigarem moradias de grupos de renda mais baixa, com assentamentos precários e irregulares. Assim, desde a primeira metade do século XX, a provisão de moradia para esse grupo econômico pelo Estado se deu fora do tecido consolidado, em bairros como Porto D’Antas, Lamarão, Olaria, Soledade, justificados pelo valor fundiário reduzido, produzindo habitações com custo reduzido, embora com maior ônus no que diz respeito à implantação de infraestrutura e custos de vida desses moradores. Nesta área, notou-se uma redução dos investimentos públicos em infraestrutura, mas com atuação governamental referente à implantação de projetos habitacionais da Prefeitura Municipal e Governo do Estado, além dos empreendimentos subsidiados pelo Programa de Arrendamento Residencial e o Minha Casa Minha Vida, nos últimos 14 anos.

Contraditoriamente, outro ponto de destaque foi a intensificação da produção habitacional em bairros já verticalizados, como 13 de Julho, Jardins, Grageru. Estes foram consolidados como local de moradia de famílias de maiores rendimentos, com condomínios de 1 ou 2 blocos, cuja apropriação se constitui um relevante mecanismo de apropriação do capital, adensando os escassos vazios existentes e valorizando, por conta disso, os imóveis a venda, sobretudo no entorno do shopping Jardins, nos novos loteamentos Garcia e Jardim Europa. Atrelado à isso, a chegada de empreendimentos econômicos como boutiques de capital local, lojas de franquias nacionais, escolas, hospital, centro médico, supermercado, restaurantes auxiliou na formação de uma nova centralidade, direcionada à clientela de luxo, homogeneizando social e economicamente esses espaços. 


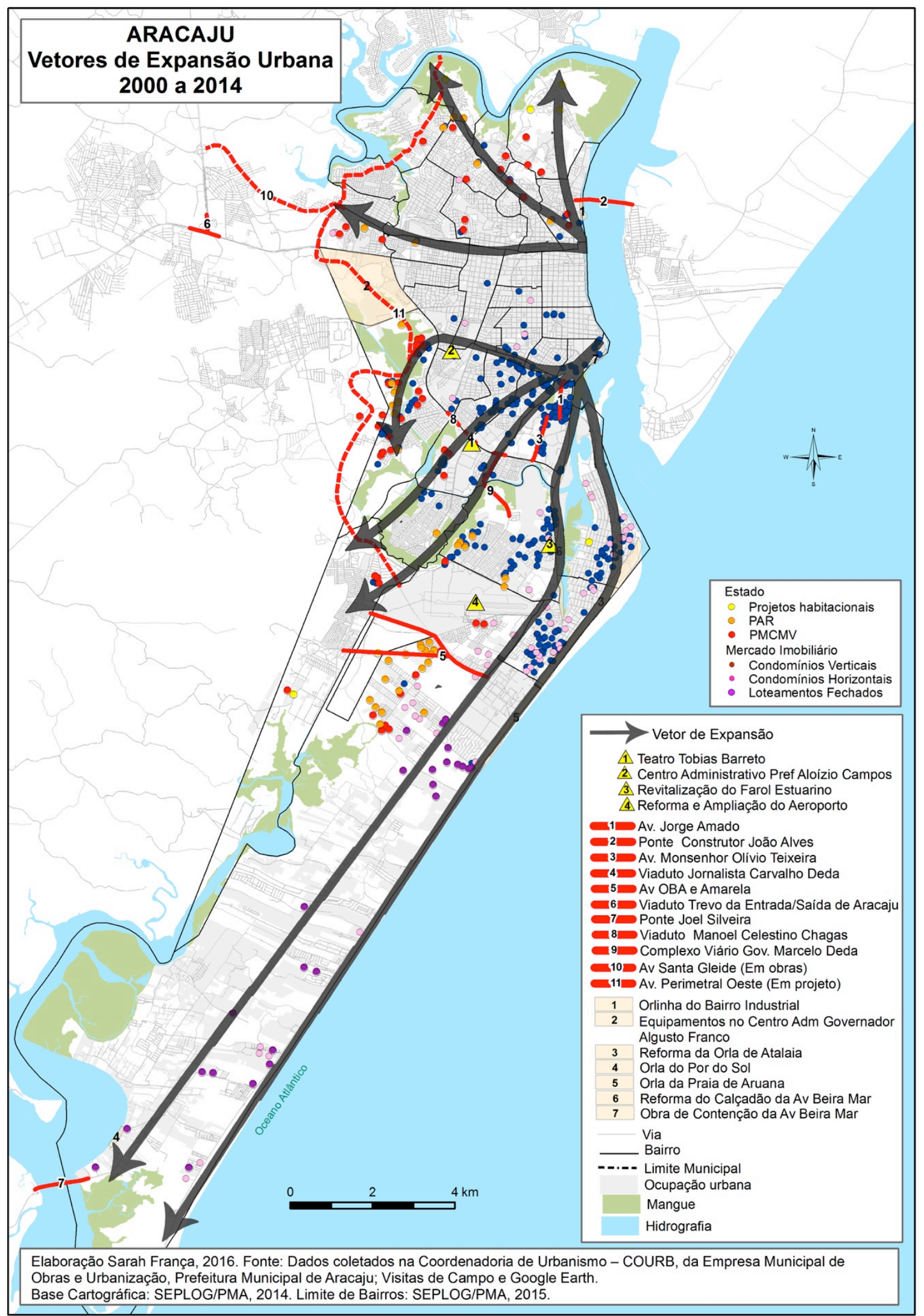

Gráfico 7: Aracaju, Vetores de Expansão Urbana, 2000-2014. Elaboração Sarah França, 2016. 
Nessa proximidade, o bairro Luzia, caracterizado antes, pela presença de conjuntos habitacionais subsidiados pelo Banco Nacional de Habitação, hoje aponta a duas novas áreas de atuação do mercado imobiliário, com a inserção de condomínios verticais. A primeira corresponde à Alameda das Árvores, uma avenida construída sob responsabilidade de apenas uma construtora, com seus prédios verticais às suas margens, enquanto a segunda, nas proximidades da avenida Adélia Franco, foi ocupada com vários empreendimentos verticais de grande porte (até 12 blocos de 16 pavimentos cada), o que faz este bairro despontar no quesito quantidade de unidades habitacionais.

Dois outros bairros foram alvo da intervenção da iniciativa privada associada à atuação do Estado. O primeiro, o Inácio Barbosa, que recebeu equipamentos públicos e privados, atrelados à construção do Complexo Viário Marcelo Déda, composto por três intervenções viárias, de interligação entre bairros. Posteriormente, alterações não só nas tipologias habitacionais predominantes (residências unifamiliares para multifamiliares), mas também para uso comercial e de serviços, permitindo a chegada de novos agentes e usuários do espaço produzido. Nesse caso, fica visível observar que o "anúncio" prévio de uma intervenção urbanística serviu como elemento atrativo para a apropriação do espaço pelo mercado imobiliário, na tentativa de formação de um novo espaço para verticalização, e assim, captação de maior lucro.

Já o bairro Farolândia, desponta em função da presença de novos condomínios verticais atraídos cuja atratividade da Universidade Tiradentes, como polo gerador de demanda por moradia para classe de renda média, somada à Revitalização da praça do Antigo Farol, fortaleceram a área para apropriação do mercado imobiliário. Em outras imediações do bairro, diferentes tipologias habitacionais são inseridas como, contraditoriamente pode-se destacar o condomínio horizontal mais luxuoso de Aracaju, nas imediações do Parque dos Cajueiros, ou empreendimentos do PAR e do PMCMV na porção mais oeste, na franja do conjunto Augusto Franco.

Novos vetores de expansão também foram apontados em áreas pouco exploradas pela incorporação até 2000, fora do eixo Jardins/13 de Julho/Grageru, como os bairros Atalaia, Coroa do Meio (vetor sul) e Luzia (vetor sudoeste). Esses dois primeiros foram isentos de ocupação vertical, em detrimento do controle da legislação federal, referente ao cone do Farol Marítimo, até o final da década de 1990. Posteriormente, a paisagem do bairro Atalaia se transformou, de predominantemente horizontal, para traços verticais especialmente na porção mais sul, cuja terra é mais valorizada, aproveitando fatores como proximidade da praia e facilidade de acesso ao Centro.

No caso das áreas antes inexploradas pela incorporação imobiliária predomina a orientação ao oeste para o bairro Jabotiana, próximo aos limites entre Aracaju e São Cristóvão. A produção habitacional nesse bairro se caracteriza de forma fragmentada e segregada, através de empreendimentos dos Programas de Arrendamento Residencial e Minha Casa Minha Vida, em sua maioria, condomínios verticais construídos pelo capital e Estado, ocorrendo intercaladamente ou mesmo avançando sobre áreas de preservação ambiental, como mangues e lagoas. Entretanto, as intervenções viárias realizadas de ligação dessa área com os outros bairros proporcionaram cada vez mais acelerado a ocupação desses espaços, sem infraestrutura e com condições ambientais frágeis, acirrando problemas como ocorrência de enchentes no período de chuvas.

Dando continuidade aos vetores indicados ao oeste, a partir dos bairros Jardins e Grageru, observa-se a ocupação no bairro Jabotiana no extremo, e do São Conrado até o Santa Maria (fortalecendo este como vetor de expansão sudoeste). Nesses nota-se presença de empreendimentos habitacionais do PAR e PMCMV, construídos sob a responsabilidade do Estado, mas também, apontando a atuação do mercado imobiliário com implantação de condomínios verticais.

O bairro Jabotiana, assim como a ZEU, um dos maiores vetores de expansão urbana de Aracaju, se fortaleceu a partir de 2002, com a implantação de conjuntos verticais do Programa de Arrendamento Residencial. Nos anos seguintes, a implantação do cemitério-parque Colina da Saudade, trouxe a circulação de um novo público e contribuiu para possibilitar a atração de novos investimentos privados e públicos, além da modificação dos usos nas principais avenidas, apontando a formação de uma nova centralidade de comércio e serviços locais. A partir de 2009, o PMCMV, em especial com empreendimentos fechados destinados à faixa de 3 a 10 salários mínimos é responsável por intensificar o preenchimento dos vazios de forma fragmentada, apesar de oferecer condições incipientes de saneamento básico, especialmente drenagem urbana, somados à infraestrutura viária, sem planejamento para suportar o atendimento dessas novas famílias ali residentes.

De forma semelhante, ao sul, o fortalecimento dos vetores traçados, nas duas últimas décadas do século XX, despontou na ZEU como uma forte tendência para apropriação do capital, com inúmeros loteamentos 
fechados e condomínios horizontais para veraneio, localizados ao longo das Rodovias dos Náufragos e Inácio Barbosa. Isso está associado às intervenções viárias executadas pela Prefeitura e pelo Governo Estadual, com o propósito de facilitar o acesso não só daqueles que ali residem, mas aos que usufruem das praias. Assim, a segregação e fragmentação do espaço ganharam maior força a partir de 2000 , especialmente na porção norte, com a implantação dos conjuntos habitacionais do PAR e do PMCMV, baseadas na permissividade das normas do Plano Diretor, e nas intervenções urbanísticas realizadas pelo Estado, como abertura de vias (OBA e Amarela), a construção das orlas de Aruana e Mosqueiro valorizaram a área.

O alto valor da terra em áreas urbanizadas é considerado um fator de dificuldade para escolha por ocupar bairros centrais, a depender do produto imobiliário a ser trabalhado. Essa questão auxilia na compreensão da escolha da localidade para construção de empreendimentos que demandam mais área, como os conjuntos habitacionais construídos pelo Estado, direcionados para uma classe popular, fato este que possibilitou nesta localidade, a construção do complexo habitacional pela Prefeitura Municipal (cerca de 2500 moradias), hoje denominado bairro 17 de março.

Por outro lado, também foram inseridos condomínios horizontais e loteamentos fechados, atendendo famílias de renda mais elevada que buscam segunda residência para veraneio e finais de semana, caracterizados pela segregação e homogeneização social. De fato, a implantação desses produtos, demanda localização privilegiada com a presença de amenidades naturais, o que somado à ausência de glebas, reduz a sua oferta em áreas mais centrais, distanciando-os para fora da malha urbana consolidada. A fragmentação e dispersão do espaço, face à deficiência de infraestrutura e serviços públicos, acirrando sérios entraves ambientais, como também ocorre no bairro Jabotiana, deve ser objeto de urgente análise nos processos de planejamento urbano na gestão municipal.

Contudo, ficou evidenciada a continuidade da apropriação de áreas pelo mercado imobiliário e pelo Estado, fortalecida pelas intervenções urbanísticas, e que ainda têm direcionado a expansão não só para as margens do tecido consolidado, como para fora dos limites municipais. Por outro lado, fica claro que surgem novas áreas em expansão, em direção à espaços sem oferta de saneamento básico, fragmentando o tecido urbano e acirrando conflitos socioambientais, para abrir frentes de atuação do capital privado.

\section{REFLEXÕES FINAIS}

A partir do exposto, ficou evidente que esses dois agentes se envolveram na produção do espaço capitalista de Aracaju, e se sobrepuseram a favor da formação e consolidação dos vetores de adensamento e expansão urbana. Desse jogo de interesses dos diversos agentes resultou um novo tipo de urbanização, marcada, a partir de 2000, sobretudo pela extensão e descontinuidade do tecido urbano, proporcionando caráter complexo às novas formas segregadas, extrapolando limites administrativos, principalmente no que diz respeito aos hábitos de consumo e às práticas socioespaciais da população.

A combinação entre multiplicidade de agentes e diferenciação de renda e de ciclo dos compradores tornou o mercado particularmente segmentado, social e espacialmente. De um modo geral, as pesquisas convergiram na certificação de que a produção habitacional formal foi predominante assumida pelos incorporadores imobiliários (construtoras, proprietários fundiários, corretoras), proporcionada para as classes média-alta e alta. Esse mercado é restrito, especulativo e excludente, sendo, na maioria das vezes, sob a forma de incorporação residencial através de condomínios fechados.

Por esse motivo, a urbanização dispersa permitida, através de uma legislação fragmentada que não reflete as reais potencialidades da cidade, trouxe sérios transtornos à população. Verifica-se a necessidade de um Plano Diretor efetivo, com diretrizes efetivas para um zoneamento diferenciado, elaborado em função do potencial construtivo, infraestrutura e sistema viário. A fragmentação das normas propiciou a explosão de empreendimentos fechados para os vetores norte, oeste e extremo sul, que correspondem às áreas carentes de infraestrutura. Outro resultado foi o acirramento das problemáticas apresentadas em áreas adensadas e verticalizadas, à leste e sul de Aracaju.

\section{REFERÊNCIAS BIBLIOGRÁFICAS}

Aracaju. Lei ${ }^{\circ} 42$ de 06 de outubro de 2000. Institui o Plano Diretor de Desenvolvimento Urbano de Aracaju e dá outras providências. Aracaju, SE. 06 de outubro de 2000. 
Araújo, Rozana Rivas de (2011). As relações entre as transformações econômicas e o ritmo da produção do espaço urbano. Estudo de caso: Aracaju. Tese de Doutorado. Universidade Federal do Rio Grande do Sul.

França, Sarah Lúcia Alves (2016). Estado e Mercado na produção contemporânea de habitação em AracajuSE. Tese de Doutorado. Niterói: Universidade Federal Fluminense.

--- (2011): A produção do espaço na Zona de Expansão de Aracaju/SE: dispersão urbana, condomínios fechados e políticas públicas. Dissertação de Mestrado. Niterói: Universidade Federal Fluminense.

França, Vera Lúcia Alves (1999). Aracaju: Estado e Metropolização. São Cristóvão: UFS.

Lefebvre, Henry (2001). O direito à cidade. São Paulo: Centauro.

Secretaria Municipal de Planejamento, Orçamento e Gestão; FRANÇA, Vera L. A. (2014) Diagnóstico da Cidade de Aracaju. Relatório Final. Etapa 03. Aracaju: PMA/SEPLAN. 